\title{
Specificity of salt appetite elicited by hypovolemia ${ }^{1,2}$
}

JOHN E. JALOWIEC AND JOSEPH E. CRAPANZANO, FAIRFIELD UNIVERSITY EDWARD M. STRICKER, UNIVERSITY OF PENNSYLVANIA

It has previously been shown that hypovolemia in rats induces an increased intake of sodium chloride solutions. The present experiment demonstrates that hypovolemic rats ingest increased amounts of solutions containing other sodium salts, but show no preferential consumption of sodium-free solutions. This suggests that a specific appetite for sodium is elicited by hypovolemia.

It is well known that sodium deficiency in rats, characterized by decreased plasma volume and sodium concentration, will lead to an increased intake of sodium chloride solutions. Further experiments have revealed that this appetite is specific for sodium and will appear when other sodium-containing salts are presented in solution (Handal, 1965; Nachman, 1962). It has recently been discovered that subcutaneous injection of polyethylene glycol (PG) solution, which causes a depletion of plasma volume without altering the sodium concentration (Stricker, 1966), also produces an increased sodium chloride intake which appears $24 \mathrm{hr}$. after injection (Stricker \& Wolf, 1966). The present experiment determines whether isonatremic PG-treated rats will ingest increased amounts of other sodium-containing solutions, and whether the presence of sodium ion is necessary for increased ingestion to occur.

Method

Thirty-six adult male Charles River Sprague-Dawley rats, weighing approximately $400 \mathrm{gm}$, were randomly divided into six groups of six rats. Each day they were given Purina Chow but no fluids for $23 \mathrm{hr}$. in their home cages, and distilled water as well as a test solution (but no food) for $1 \mathrm{hr}$. in other identical cages. Each group received a single test solution throughout the experiment. The fluids were presented in graduated tubes fitted with metal drinking nozzles, and their relative positions were kept constant. Testing began after two days of adaptation to this schedule. Each rat was injected once with $5 \mathrm{ml}$ of $20 \%$ PG in Ringer's solution and once with $5 \mathrm{ml}$ of the vehicle, with the order of injection counterbalanced within each group. The injections were given subcutaneously at the end of the drinking periods of the third and fifth days, after which the rats were deprived of both food and fluids for $23 \mathrm{hr}$. Each group was then given water plus one of the following six test solutions: $.15 \mathrm{M}$ sodium phosphate $(\mathrm{pH}=7), .15 \mathrm{M}$ sodium acetate, .015 $\mathrm{M}$ sodium chloride, .15 M calcium chloride, .15 M potassium chloride, and $.30 \mathrm{M}$ dextrose. Intakes of water and test solution measured at $5 \mathrm{~min}$. intervals for the first $15 \mathrm{~min}$. of the subsequent $60 \mathrm{~min}$. test periods comprised the main experimental data.

\section{Results and Discussion}

Figure 1 shows that PG treatment resulted in large increases in the intake of each of the three solutions containing the sodium ion ( $p^{\prime} s<.05$ for individual groups and $\mathrm{p}<.001$ for the three groups combined by two-tailed correlated $t$ tests of $15 \mathrm{~min}$. scores). These effects became apparent quite early in the test period and generally reached statistical significance by the end of the first $5 \mathrm{~min}$. of drinking. In contrast, PG treatment had no apparent effect upon the intake of the calcium chloride and dextrose solutions, and induced a relatively small though statistically significant $(p<.05)$ increase in the intake of the potassium chloride solution.

There was also a general increase in water intake across all groups as a result of PG treatment, from a mean of $1.8 \mathrm{ml}$ after vehicle injection to a mean of $3.3 \mathrm{ml}$ after $P G$ injection $(p<.01)$. This result is in accord with earlier findings that water intake increases after PG treatment (Stricker, 1966) and indicates that thirst must be considered in the interpretation of the main results. For example, it is possible that the intake of a test solution which is not so aversive that it is completely avoided (e.g., calcium chloride) nor is so preferred that it is consumed to the exclusion of water (e.g., dextrose) might be indiscriminately increased as a result of thirst rather than as a result of a specific appetite for that solution. It thus seems desirable to analyze changes in preference for, as well as changes in absolute intake of, the sodium and potassium solutions to obtain another index of preference behavior.

Preference scores for the test solutions (i.e., the

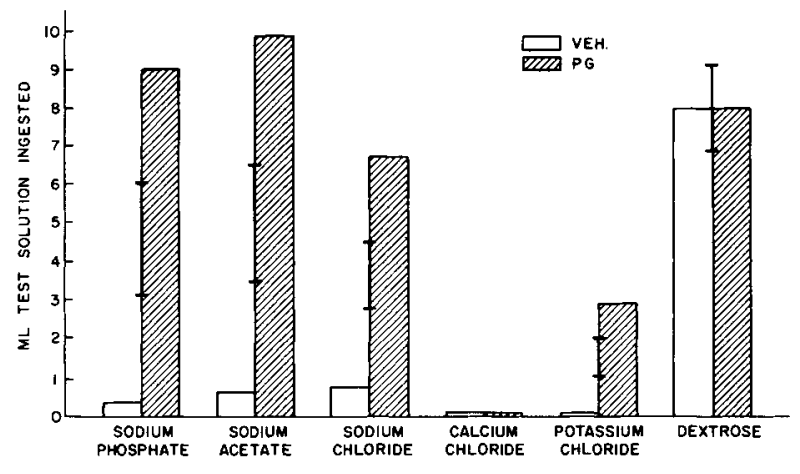

Fig. 1. Ingestion of test solutions during a $15 \mathrm{~min}$. period following injection of either $5 \mathrm{ml}$ of Ringer's solution (vehicle) or $5 \mathrm{ml}$ of $20 \%$ polyethylene glycol (PG). 
Table 1. Mean preference scores for the test solutions.

\begin{tabular}{lcc} 
Test Solution & \multicolumn{2}{c}{ Treatment } \\
\hline $.15 \mathrm{M}$ sodium phosphate & .087 & $20 \% \mathrm{PG}$ \\
$.15 \mathrm{M}$ sodium acetate & .211 & .624 \\
$.015 \mathrm{M}$ sodium chloride & .578 & .861 \\
$.15 \mathrm{M}$ calcium chloride & .000 & .670 \\
$.15 \mathrm{M}$ potassium chloride & .019 & .000 \\
$.30 \mathrm{M}$ dextrose & .990 & .459 \\
\hline
\end{tabular}

ratio of intake of test solution to total fluid intake) are presented in Table 1. A relative aversion to the sodium phosphate and the sodium acetate solutions was found after vehicle injection, but a relative preference was found after PG injection $(p<.01$ for both groups combined). There was no significant effect of PG treatment upon the relative performance for the $.015 \mathrm{M} \mathrm{NaCl}$ solution; however, previous work has demonstrated a significant increase in preference for an initially aversive $.33 \mathrm{M} \mathrm{NaCl}$ solution $24 \mathrm{hr}$. after treatment with 20\% PG (Stricker \& Wolf, 1966). Thus, increased intake of the solutions containing sodium salts cannot be accounted for by indiscriminant effects of thirst, but instead seem to be due to a specific sodium appetite.

Similarly, there was a decrease in aversion for the potassium chloride solution following PG treatment, but this was neither statistically reliable nor did it become an actual preference. The observed change in preference might well be accounted for by an increased thirst, although it is conceivable that the PG treatment might have affected potassium appetite in some rats. In this regard, Falk (1965) has recently reported that intraperitoneal dialysis treatments leading to sodium deficiency and an increased appetite for sodium chloride solutions may produce an increased appetite for potassium chloride solutions as well. However, other data in the present study also support the conclusion that increased intake of solutions containing sodium following PG treatment was due to a specific appetite for sodium, whlle increased intake of the potassium chloride solution was due to thirst and relatively indiscriminant choice behavior. On the days preceding and intervening between the vehicle and PG tests, the rats were given Purina chow ad lib during the $23 \mathrm{hr}$. fluid deprivation periods. The ingestion of food increased thirst, with the total fluid intake in the subsequent $1 \mathrm{hr}$. test period being somewhat higher than that following PG injection and food deprivation. Nevertheless, the three groups given solutions containing sodium ingested substantially more test solution after PG than after ad lib food ( $p$ 's $<.05$ for sodium acetate and sodium phosphate, and $p<.10$ for sodium chloride), whereas the group drinking the potassium chloride solution ingested less test solution after PG than after ad lib food $(p<.10)$.

The present data thus indicate that rats made hypovolemic by PG treatment are thirsty and also have a specific appetite for solutions containing sodium salts. This might be expected from physiological considerations, since hypovolemia is most efficiently corrected by repletion of sodium and water. Since only the solutions containing sodium salts of those used in this experiment remain largely extracellular after ingestion, none of the sodium-free solutions would be expected to effectively restore intravascular fluid volume and thereby reduce the stimuli for thirst and sodium appetite. In this regard, recent work has demonstrated that plain water will neither repair hypovolemia nor eliminate the associated thirst (Stricker \& Wolf, in press) and sodium appetite (Wolf \& Stricker, unpublished data).

The physiological mechanisms by which sodium appetite is elicited during hypovolemia are at present unknown. One hypothesis suggests that sodium appetite arises as a result of the increased secretion of aldosterone during hypovolemia. A proposed model for sodium appetite regulation incorporating this hypothesis and discussing the relation between sodium appetite and hypovolemic thirst has been presented elsewhere (Stricker \& Wolf, 1966).

\section{References}

Falk, J. L. Limitations to the specificity of $\mathrm{NaCl}$ appetite in sodium-depleted rats. J. comp. physiol. Psychol., 1965, 60, 393-396.

Handal, P. J. Immediate acceptance of sodium salts by sodium deficient rats, Psychon. Sci., 1965, 3, 315-316.

Nachman, M. Taste preferences for sodium salts by adrenalectomized rats. J. comp. physiol. Psychol,, 1962, 55, 1124-1129.

Stricker, E. M. Extracellular fluid volume and thirst. Amer. J. Physiol., 1966, 211, 232-238.

Stricker, E. M., \& Wolf, G. Blood volume and tonicity in relation to sodium appetite. J. comp. physiol. Psychol., 1966, 62, (in press).

Stricker, E. M., \& Wolf, G. Hypovolemic thirst in comparison with thirst induced by hyperosmolarity. Physiol. Behav., in press. Notes

1. Supported by USPHS grant MH00647.

2. The authors are thankful to Dr. George Wolf for assistance in the design and analysis of the experiment. 